\title{
A comprehensive study of hygroscopic properties of calcium- and magnesium- containing salts: implication for hygroscopicity of mineral dust and sea salt aerosols
}

\section{Liya Guo et al.}

Correspondence to: Mingjin Tang (mingjintang@gig.ac.cn)

The copyright of individual parts of the supplement might differ from the CC BY 4.0 License. 


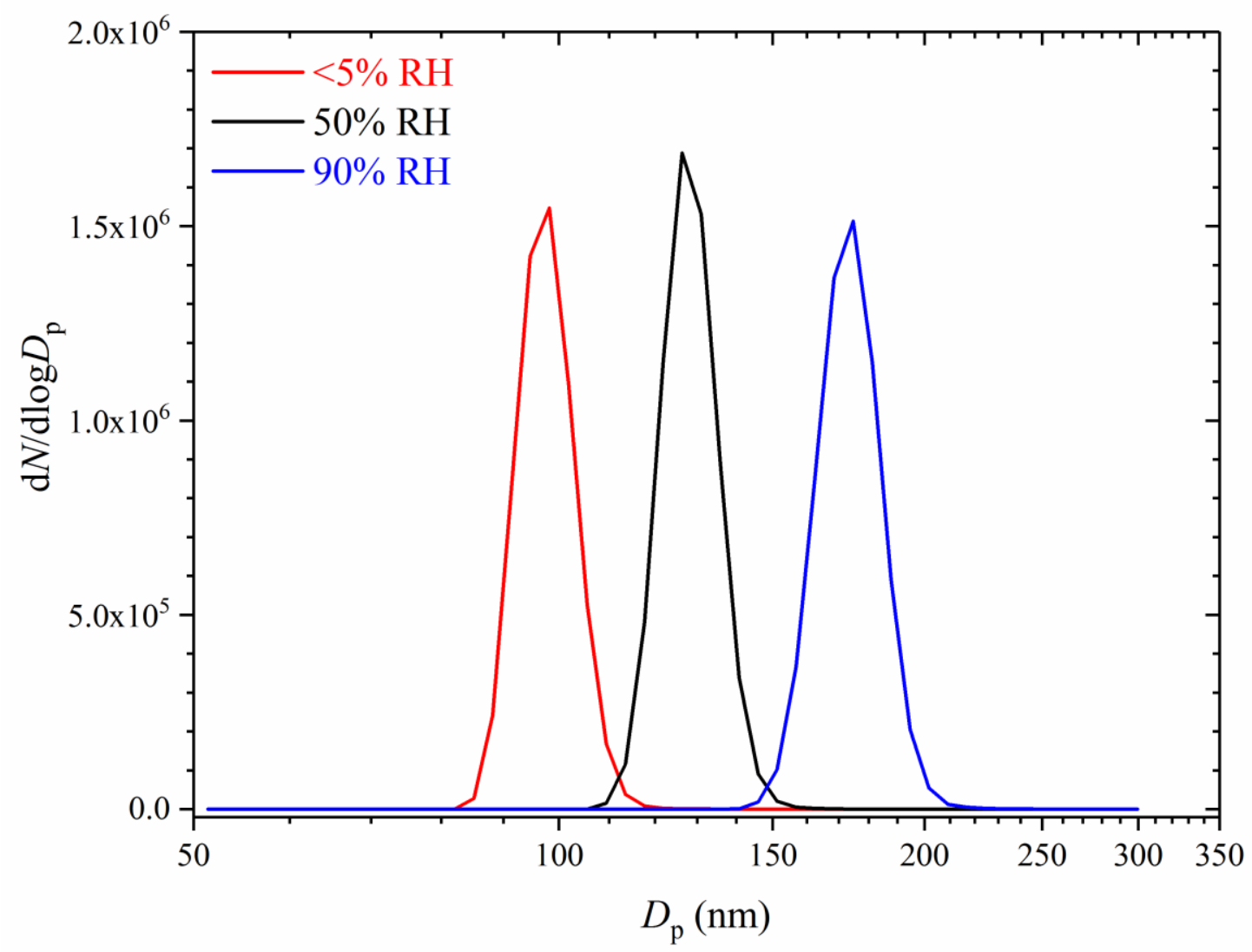

11

Figure S1. Number size distribution of $\mathrm{Ca}\left(\mathrm{NO}_{3}\right)_{2}$ aerosol particles (with a dry mobility diameter

13 of $100 \mathrm{~nm}$, as selected using a differential mobility analyzer) at $<5,50$ and $90 \% \mathrm{RH}$.

14 